Relations industrielles

Industrial Relations

\title{
Le partage de l'emploi, vers une société sans chômage, par Bernard Delplanque, Paris, Éditions Entente, 1980, 141 pp.
}

\section{Paul Beaulieu}

Volume 37, numéro 1, 1982

URI : https://id.erudit.org/iderudit/029248ar

DOI : https://doi.org/10.7202/029248ar

Aller au sommaire du numéro

Éditeur(s)

Département des relations industrielles de l'Université Laval

ISSN

0034-379X (imprimé)

1703-8138 (numérique)

Découvrir la revue

Citer ce compte rendu

Beaulieu, P. (1982). Compte rendu de [Le partage de l'emploi, vers une société sans chômage, par Bernard Delplanque, Paris, Éditions Entente, 1980, 141 pp.] Relations industrielles / Industrial Relations, 37(1), 248-248.

https://doi.org/10.7202/029248ar

Tous droits réservés (C) Département des relations industrielles de l'Université Laval, 1982
Ce document est protégé par la loi sur le droit d'auteur. L'utilisation des services d'Érudit (y compris la reproduction) est assujettie à sa politique d'utilisation que vous pouvez consulter en ligne.

https://apropos.erudit.org/fr/usagers/politique-dutilisation/ 
tions de travail et de paye». La célèbre Commission Donovan va encore parler en 1968 de ce défaut maladif de négociation chez Ford.

Cet apprentissage, somme toute assez lent, dont les indices se multiplient dans le présent volume, me rend difficile d'avaler le rapprochement implicite que font les auteurs entre Ford et les progrès du mouvement féministe. L'éclatement des revendications ouvrières de l'année 1968, généralisé à travers l'Europe, m'apparaît comme une brèche dans la résistance de la croute sociale à des poussées antérieures qui relèvent d'une dynamique plus fondamentale que celle des relations industrielles. Ce serait pur «tripotage» historique que de mettre au centre des événements ici décrits, la poussée féministe des 20 dernières années. Les performances rétrogrades de Ford en relations de travail, la situation économique désastreuse en Grande-Bretagne et l'effritement du «bon ententisme» exemplaire qui marquent traditionnellement les rapports collectifs de travail en Angleterre suffisent abondamment à établir la causalité dont ont ici besoin les auteurs.

On ne peut, d'autre part, qu'être d'accord avec eux dans leur plaidoyer en faveur d'études de relations de travail réalisées par des praticiens expérimentés plutôt que par de simples théoriciens: le progrès réalisé se situant au domaine des connaissances contextuelles et dans la possibilité de décomposer en ses composantes quotidiennes des événements trop complexes. La seule précaution à prendre avec cette méthode est qu'elle n'élimine en rien le besoin de garder du recul et de la perspective.

En tant que riche document, ce volume a le défaut de sa qualité, c'est-à-dire qu'il peut concurrencer un roman russe dans le nombre de ses personnages: plus de 90 noms différents se disputent notre intérêt et près de 35 abbréviations différentes émaillent un texte qui en devient difficile.

\section{Hervé GAUTHIER}

Université Laval
Le partage de l'emploi, vers une société sans chômage, par Bernard Delplanque, Paris, Éditions Entente, 1980, 141 pp.

Ce livre aurait pu très bien s'intituler «Éloge du modèle socio-technique». Il propose d'entammer une réflexion sur la question de la recherche du plein emploi par une macro-ré-organisation du travail de production.

L'auteur, après une vive critique de l'économie d'expansion trace les grands traits d'un nouveau modèle socio-culturel qui tendrait à établir un juste équilibre entre le pôle technique et le pôle social de la vie économique. Il propose de rechercher d'autres formes d'organisation sociale du travail. Le postulat de base du modèle proposé consiste dans l'observation que la société continue à vouloir «organiser la vie des gens autour du travail industriel alors que c'est ce qui se passe pendant le non-travail qui les intéresse». Ainsi, les frontières de l'entreprise de production seraient appellées à devenir de plus en plus poreuses, au point qu'il serait alors difficile de savoir où commence et où finit l'entreprise. L'auteur avance catégoriquement, sans toutefois en faire une démonstration rigoureuse, que la coupure travail-loisirs n'est plus possible.

Le modèle proposé se nomme la sociotechnie. L'ère de la sociotechnie devrait remplacer l'industrie. C'est un modèle qui reprend sur un plan macro-économique les principes fondamentaux de l'approche de la qualité de vie au travail.

Ce livre, audacieux dans son énoncé, quoique trop bref dans son développement, ne fait qu'identifier l'objet de la préoccupation de son auteur sans entrer vraiment dans une analyse étoffée de l'articulation du modèle proposé. Il a toutefois le mérite de stimuler la réflexion et d'attirer l'attention sur le besoin crucial pour notre temps d'innover dans l'organisation macro-économique de la production.

Paul beaulieu

Université Laval 